\title{
Espacio Crítico
}

\section{A. El PAPEL DEL ANTROPÓlOGO EN LA PROTECCIÓN DE LOS DERECHOS HUMANOS DE LOS PUEBLOS INDÍGENAS ${ }^{1}$}

\section{David Martín Castro²}

Antropólogo. Durante los últimos años ha trabajado para la Organización de las Naciones Unidas y para el Ministerio de Asuntos Exteriores y de Cooperación de España en temas ligados con la defensa de los derechos humanos de los pueblos indígenas. E-mail: dmartincastro@cps.ucm.es

\begin{abstract}
Resumen
El texto es una reflexión sobre el papel que el autor considera deben jugar los antropólogos en su relación con los pueblos indígenas. El autor recoge la percepción y critica de algunos representantes indígenas hacia los antropólogos e intenta responder a los motivos que les llevan a dicha crítica.

\section{Palabras clave}

Pueblos indígenas, cooperación técnica, derechos humanos, subjetividad.
\end{abstract}

\begin{abstract}
This text reflects the author's thoughts on the role anthropologists should play on their relationships with indigenous peoples. The author highlights the perception and criticism that some indigenous representatives have on regard to anthropologists and tries to answer the causes of this criticism.
\end{abstract}

\section{Key words}

Indigenous peoples, technical cooperation, human rights, subjectivity.

\footnotetext{
${ }^{1}$ Este texto no pretende ser un artículo científico sino simplemente es una reflexión basada en mi propia experiencia personal. Con ello, se pretende expresar una forma personal de trabajar en antropología respetuosa con los derechos de los pueblos indígenas.

${ }^{2}$ Este texto hará referencia constante al proceso de discusión de la Estrategia de la Cooperación Española con los pueblos indígenas, proceso en el que he trabajado en diversos momentos de mi carrera profesional. En 2003, estuve trabajando en la definición de uno de los borradores iniciales durante un año para la elaboración de un borrador de trabajo definitivo. Posteriormente, en 2005 fui contratado por la Agencia Española de Cooperación Internacional para la elaboración del borrador técnico a partir de las propuestas de ONGD especializadas, expertos, etc. Posteriormente, fui contratado como consultor externo por el Ministerio de Asuntos Exteriores y de Cooperación para la elaboración del documento final y para coordinar su contenido con el resto de estrategias sectoriales de la cooperación española (salud, educación, medioambiente, cultura y desarrollo, etc.). Asimismo he trabajado para la Oficina del Alto Comisionado de las Naciones Unidas para los Derechos Humanos en la unidad responsable de atender los asuntos de los pueblos indígenas.
} 


\section{El proceso de elaboración de la Estrategia de la cooperación española con los pueblos indígenas}

$\mathrm{D}^{\mathrm{s}}$ espués de más de 5 años de espera y de negociación, la Estrategia de la cooperación española con los pueblos indígenas (ECEPI) entra en lo que parece ser su última fase de discusión y aprobación por parte de la secretaría de estado de cooperación internacional (SECI) ${ }^{3}$. El texto final será el resultado de un proceso participativo en el que han intervenido Organizaciones no Gubernamentales de Desarrollo (ONGD) especializadas en la cooperación con los pueblos indígenas, expertos independientes, funcionarios del Ministerio de Asuntos Exteriores y de Cooperación (MAEC) y de la Agencia Española de Cooperación Internacional (AECl), y representantes indígenas latinoamericanos.

En caso de ser aprobada, la ECEPI será el documento de mayor relevancia elaborado por el MAEC referente a los pueblos indígenas. En ella se establecerán las prioridades sectoriales y geográficas, los instrumentos de cooperación aplicables y los marcos en los que se distribuirán los recursos y fondos de la cooperación española. A pesar de que la ECEPI no tiene la capacidad práctica de obligar a todas las administraciones públicas o privadas a respetar sus directrices, la experiencia muestra que en aras de una mayor coordinación y eficacia, la mayor parte de los actores de la cooperación española, públicos o privados, se atendrán a las líneas estratégicas marcadas por la ECEPI, en consonancia con el liderazgo que el MAEC y la AECI viene manteniendo en España en este sentido. Por tanto, cualquier proyecto de cooperación en el ámbito de los pueblos indígenas que no se ajuste a estas directrices difícilmente podrá ser financiado por los organismos públicos españoles.

En cuanto a su contenido y en relación con la antropología, en las discusiones mantenidas, en ningún momento se destacó la necesidad de financiar investigaciones antropológicas en el ámbito de los pueblos indígenas, aunque sí se llevó a la discusión la necesidad de financiar otras de carácter económico y legal ${ }^{4}$. Todo ello a pesar de que el Plan Director de la Cooperación Española 2005-2008 ${ }^{5}$ (PD 2005-2008) sí prevé la financiación de investigaciones antropológicas en el ámbito de la cultura. Ha sido posteriormente, en las discusiones específicas con respecto al futuro contenido de la ECEPI, en las que se decidió no hacer referencia a las mismas. No obstante, tanto la persona central en la elaboración de esta estrategia como la asistencia técnica que fue contratado para condensar las aportaciones y realizar la redacción final de la ECEPI, y que suscribe este ensayo, se consideran antropólogos. En este sentido, mi trabajo en el proceso de elaboración de la ECEPI responde a una forma de entender la antropología y el trabajo del antropólogo en el ámbito internacional de los

\footnotetext{
${ }^{3}$ Debido a que la estrategia aún no ha sido presentada, en este texto se hablará del proceso de discusión y no tanto de su contenido final. La Secretaria de Estado de cooperación Internacional puede decidir aprobar la ECEPI, relegarla para un momento posterior o, incluso, no aprobarla y volver a comenzar un nuevo proceso.

${ }^{4}$ La ECEPI será principalmente un documento legal y por tanto se refiere a los pueblos indígenas como "sujetos de derecho, tanto individuales como colectivos".
} 
derechos humanos y de la cooperación técnica con los pueblos indígenas, en la que prima la libertad y los derechos de los pueblos indígenas por encima de cualquier otra consideración.

Así, por ejemplo, en las discusiones mantenidas, los expertos no se plantearon realmente hacer una definición del contenido exacto de los términos pueblos indígenas, más allá de recoger las definiciones más comunes y de mayor importancia en el ámbito internacional. Lo que si se evidenció fue la necesidad de eliminar cualquier concepción culturalista o de rasgos que les definan como tal. Lo más cercano que se discutió durante la última etapa del proceso de elaboración fue la de afirmar que la autoidentificación debía ser un factor determinante a la hora de definir a un pueblo como indígena ${ }^{6}$.

En este punto, al igual que en muchos otros, la discusión en la elaboración de la ECEPI se diferenció de la Estrategia española de cooperación con los pueblos indígenas de 1997, a la que vendrá a sustituir una vez aprobada. La Estrategia de 1997 definía los pueblos indígenas de una forma eminentemente cultural y ligada con la idea del "indio bueno"7. La estrategia de 1997 también fue escrita por un antropólogo, si bien, como se verá, la visión de la que partía es diferente a la mantenida en el proceso de elaboración de esta nueva estrategia. Este cambio también se debe a los 9 años transcurridos desde la publicación de la anterior estretegia. Si bien la estrategia de 1997 resaltaba la importancia de la continuidad de las culturas y tradiciones de los pueblos indígenas, en la discusión de la estrategia actual, siguiendo la tendencia internacional en cuanto a la protección de derechos de los pueblos indígenas, se dejó de lado lo que sería el contenido de esas culturas y las remitió a la decisión que pudieran tomar los miembros de los pueblos indígenas ${ }^{8}$.

\footnotetext{
${ }^{5}$ Documento de máximo rango normativo dentro de la política de planificación de la cooperación española y al que el resto de los documentos de cooperación deben ajustarse; solo las Leyes de Cooperación tienen un rango jerárquico superior dentro de la cooperación española.

${ }^{6}$ Esta cuestión ha sido ampliamente defendida por los propios representantes de los pueblos indígenas en el Grupo de Trabajo sobre Poblaciones Indígenas de la extinta Comisión de Derechos Humanos. Igualmente, en el proyecto de declaración se decidió suprimir el antiguo artículo 8 puesto que los estados se opusieron vivamente a que se hicieran referencias a la autoidentificación: No obstante, el artículo 9 y 33 del texto pueden ser interpretados en ese sentido.

7 "[...]Estas sociedades, poseedoras de un vasto conocimiento del medio natural, se perfilan hoy en día como últimos guardianes de la diversidad genética de estos ecosistemas, ofreciendo una alternativa eficiente de aprovechamiento racional de la biodiversidad y del equilibrio ecológico en beneficio de su autodesarrollo y del equilibrio ecológico y autosostenible de la Humanidad en su Conjunto. Los pueblos indígenas tienen en común, aún a pesar de su enorme diversidad cultural, una serie de características que articulan una cosmovisión específica y propia, que básicamente se identifica con un fuerte sentimiento de identidad propia y de vínculo con la tierra, considerada como fuente de vida, como progenitora, que se preserva y actúa con respecto a ella con un fuerte sentimiento de reciprocidad. Poseen, asimismo, un gran conocimiento de la naturaleza, del aprovechamiento ecológico de los recursos del medio natural y una gran cohesión social a través de los mitos, los rituales y los sistemas de parentesco. El mundo de los espíritus es moderado por el chamán, que articula la armonía entre la comunidad y ese otro mundo espiritual, restableciendo la salud y la armonía cósmica a través de complicados rituales que vinculan lo social y lo psicológico, de forma que en el individuo siempre se define en función de los grupal-societario" Estrategia española de cooperación con los pueblos indígenas 1997.

${ }^{8}$ En este punto se hace eco del párrafo 70 del informe de trabajo de Erica Irene Daes, presidenta relatora del Grupo de Trabajo sobre Poblaciones Indígenas de la Comisión de Derechos Humanos (Documento E/CN.4/Sub.2/AC.4/1996/2). Erica-Irene Daes, presidenta-relatora del GTPI, matiza la anterior definición y señala una serie de factores que, si bien no constituyen ni pueden constituir una relación exhaustiva -y que pueden encontrarse en mayor o menor grado en cada pueblo indígena-, ayudan a comprender el significado y aplicación de la expresión pueblos indígenas: "La prioridad en el tiempo por la que respecta a la ocupación y el uso de determinado territorio; la perpetuación voluntaria de la distinción cultural, que puede incluir los aspectos del idioma, la organización social, la religión y los valores espirituales, los modos de producción, las leyes e instituciones; la conciencia de la propia identidad, así como su reconocimiento por otros grupos, o por las autoridades estatales, como una colectividad distinta; y una experiencia de sometimiento, marginación, desposeimiento, exclusión o discriminación, independientemente de que estas condiciones persistan o no.
} 
Asimismo, en la estrategia de 1997 se evaluaba a las culturas indígenas a partir de unos valores externos $^{9}$ al tiempo que se les reconocía la existencia de sus propios modelos de desarrollo ${ }^{10}$, aunque en ningún momento se establecían mecanismos que les permitieran llevarlos a la práctica ${ }^{11}$. Por el cotnrario, en la discusión de la estrategia de 2006, se hicieron referencias constantes a las demandas que las propias organizaciones que los pueblos indígenas vienen expresando en el ámbito internacional y la definición que ellos mismos han dado a su situación ${ }^{12}$. Igualmente, se propusieron mecanismos para que sus modelos de desarrollo puedan ser aplicados, sin basarse en ninguna presuposición de cúales iban a ser estos.

Dentro de estos mecanismos, tal y como fue recogido ampliamente en las discusiones, durante el proceso de elaboración destaca la tendencia a hacer necesaria la obtención del consentimiento libre, previo e informado de los pueblos indígenas y su participación antes de la implementación de acciones legales o administrativas en todas aquellas esferas que puedan afectarles ${ }^{13}$. En el ámbito de la cooperación este principio conlleva que los pueblos indígenas deban participar en todas las fases del proyecto para ser financiado. De esta forma, a diferencia de la estrategia de 1997, la discusión no recogió o presupuso una sola realidad sino que aceptó la existencia de muchas posibles realidades y, sin posicionarse, son los propios afectados los que tienen que definirla.

Igualmente, en la relativamente amplia bibliografía utilizada (hay que tener en cuenta que es un texto normativo) no se hizo una sola referencia a un documento escrito por algún antropólogo, más allá de los informes anuales que el Relator Especial sobre la situación de los derechos humanos y las libertades fundamentales de los indígenas ha presentado ante la Comisión de Derechos Humanos y a la Asamblea General de Naciones Unidas. De esta forma, las fuentes explícitas en las que se basa la ECEPI son muy poco antropológicas. ¿Por qué considero entonces que está fuertemente influenciada por la antropología?

\footnotetext{
9 "Los pueblos indígenas en la actualidad forman generalmente parte de las poblaciones más afectadas por la extrema pobreza. Viven en condiciones de vida notoriamente inferiores a las de la población no indígena y se caracterizan por una esperanza de vida más baja, una mayor mortalidad infantil, una deficiente o inexistente educación escolar, una mayor tasa de analfabetismo, menores oportunidades de generar ingresos y una carente o insuficiente acceso a las instalaciones de la infraestructura social. Especialmente desfavorecidas son las mujeres, los niños y los ancianos".

10 "Los pueblos indígenas en la actualidad forman generalmente parte de las poblaciones más afectadas por la extrema pobreza. Viven en condiciones de vida notoriamente inferiores a las de la población no indígena y se caracterizan por una esperanza de vida más baja, una mayor mortalidad infantil, una deficiente o inexistente educación escolar, una mayor tasa de analfabetismo, menores oportunidades de generar ingresos y una carente o insuficiente acceso a las instalaciones de la infraestructura social. Especialmente desfavorecidas son las mujeres, los niños y los ancianos".

${ }_{11}$ "La cooperación española considera que es en el marco de esta línea de especificidad que significa la existencia de culturas tan diferentes como son las indígenas, con una concepción tan diferenciada del desarrollo, en el que se debe entender la definición de una estrategia de cooperación con los pueblos indígenas".

${ }^{12} \mathrm{Si}$ bien el resultado puede ser el mismo, el proceso es muy diferente. La perspectiva que defiendo en este texto hace hincapié en la importancia del proceso y no tanto en el resultado.

${ }^{13}$ Así, por ejemplo, el artículo 20 del proyecto de declaración de las Naciones Unidas sobre los derechos de los pueblos indígenas recientemente aprobado por el Consejo de Derechos Humanos establece que "Los estados celebrarán consultas y cooperarán de buena fe con los pueblos indígenas interesados por medio de sus instituciones representativas para obtener su consentimiento previo, libre e informado antes de adoptar y aplicar medidas legislativas y administrativas que les afecten"
} 


\section{La imagen de la antropología entre representantes indígenas (unas experiencias subjetivas)}

A partir de mi propia y limitada experiencia personal en el ámbito de la protección de los derechos humanos de los pueblos indígenas, considero que el antropólogo tiene un importante papel a jugar en este ámbito, pero para ello es necesario cambiar la percepción que de la antropología parecen tener la mayor parte de los dirigentes de organizaciones indígenas que he conocido.

En este sentido, desde hace ya un buen número de años, el centro de mi trabajo como antropólogo se ha centrado en la defensa de los derechos de los pueblos indígenas. Esto me ha permitido conocer a un buen número de representantes indígenas, tener acceso a sus documentos y participar en sus reuniones. Mi primera experiencia con representantes de pueblos indígenas latinoamericanos es ilustradora de la imagen que mis interlocutores tenían de los antropólogos "no nos gustan los antropólogos". ¿Motivo? "Ellos siempre quieren hablar por nosotros y no se dan cuenta de que nosotros ya somos adultos y podemos hablar, decir como somos, lo que pensamos y en lo que creemos". En otra ocasión posterior, un representante indígena de los nativos norteamericanos tuvo la paciencia de explicarme que algunos de los libros más conocidos de la antropología estadounidense eran, para él, un insulto a su propio pueblo. De hecho, en conversaciones con otros antropólogos que han realizado trabajo de campo en tierras de pueblos indígenas, en más de una ocasión les he escuchado referirse a las dificultades que tienen para entrar en las comunidades, el rechazo que han sentido y la falta de apoyo que han recibido por parte de las organizaciones y movimientos indígenas. Ademas, tengo que reconocer que tanto durante mi participación en la ECEPI como en mi trabajo en el ámbito internacional, mi presentación como antropólogo levantó suspicacias entre la mayor parte de las personas con las que trabajé (miembros de ONGD especializadas en pueblos indígenas principalmente).

A pesar de ello, algunas de las personas con un mayor renombre en la esfera internacional para la protección de los derechos de los pueblos indígenas son precisamente antropólogos, y creo que no es una coincidencia.

Los dos casos más conocidos, pero no los únicos, son el antropólogo mexicano Rodolfo Stavenhagen y la antropóloga danesa Ida Nicolaisen. Ambos tienen un largo historial académico centrado principalmente en pueblos indígenas pero también tienen una larga experiencia en el trabajo aplicado sobre el terreno.

Rodolfo Stavenmhagen ejerce desde 2001 la labor de Relator Especial de la Comisión de Derechos Humanos sobre la situación de los derechos humanos y libertades fundamentales de los indígenas ${ }^{14}$.

\footnotetext{
${ }^{14}$ El Relator Especial es, sin lugar a dudas, el cargo individual en relación con la protección de derechos de los pueblos indígenas con mayor relevancia dentro del sistema de las Naciones Unidas. Su mandato incluye la elaboración de informes temáticos, la visita países en los que comprueba la situación de los derechos de los pueblos indígenas y el envío comunicaciones sobre violaciones de derechos de los indígenas a los gobiernos.
} 
Sus informes temáticos y de países son una de las más ricas fuentes de análisis dentro del ámbito de la protección de los derechos humanos de los pueblos indígenas. Además, estos documentos tienen una gran influencia en las políticas implementadas por los estados. A modo de ejemplo, tras algunas de sus visitas a países, han abierto debates sobre la situación de los pueblos indígenas y ha permitido abrir o continuar procesos para el reconocimiento de derechos a los pueblos indígenas.

Por su parte, Ida Nicolaisen es uno de los 16 miembros del Foro Permanente para las Cuestiones Indígenas ${ }^{15}$, a propuesta del gobierno danés, aunque recibió un amplio respaldo de parte de las organizaciones indígenas. Nicolaisen, después de trabajar en África, pasó más de 30 años en Borneo y, sólo con la sequía saheliana, regresó a África donde trabajó para la cooperación danesa en el marco de Naciones Unidas.

Además de estos dos representantes destacados, un buen número de antropólogos menos conocidos trabajan para IWGIA y mantienen unas relaciones fluidas con las organizaciones y representantes indígenas. IWGIA es actualmente una de las ONGD especializadas en el trabajo con pueblos indígenas con mejor reputación dentro de las comunidades ${ }^{16}$. Asimismo, en algunas organizaciones internacionales y agencias de cooperación, unos pocos antropólogos defienden, en su trabajo diario, una visión de la antropología específicamente centrada en la protección de los derechos humanos de los pueblos indígenas. Finalmente, algunos equipos de antropólogos (sobre todo en el ámbito de la antropología jurídica) están haciendo un trabajo extraordinario para la defensa de sus derechos humanos y se han ganado el respeto de los movimientos y organizaciones indígenas con las que trabajan. No obstante, muchos de ellos se muestran reticentes a mostrar su formación de antropólogos.

La forma en que estos antropólogos son recibidos tanto por la academia (con la excepción del caso de la antropología jurídica) como por los propios representantes indígenas es, cuanto menos, paradójica. Cojamos el caso de Rodolfo Stavenhagen. Se trata de uno de los oradores invitados para abrir las sesiones de la Federación de Asociaciones de Antropología del Estado Español en la reunión de Sevilla de 2005 y está reconocido como uno "de los grandes antropólogos de habla hispana". Así, al tiempo que ejerce su labor como Relator Especial es miembro del Colegio de México. En este sentido, es un académico de reconocido prestigio pero su trabajo en el ámbito de su mandato como Relator es desconocido y muchos de los estudiosos de su obra académica no le reconocerían en ellos (a pesar de todo, su lectura detenida me lleva a la conclusión de que sólo un antropólogo sería capaz de escribirlos tal y como él lo hace). En cuanto a la imagen que de él tienen un buen número de representantes de los pueblos indígenas, es necesario resaltar que para ellos Rodolfo Stavenhagen "no parece antropólogo". En más de una ocasión cuando, después de escuchar críticas a la antropología por parte de algún representante, les he señalado que Rodolfo Stavenhagen es

\footnotetext{
${ }^{15}$ El Foro Permanente es un órgano asesor del ECOSOC. Desde su fundación, en 2001, el Foro se ha convertido sin lugar a dudas, junto con el Grupo de Trabajo para las Poblaciones Indígenas, de la Comisión de Derechos Humanos, en el centro de la concertación internacional en defensa de los derechos de los pueblos indígenas.

${ }^{16}$ Especialmente interesante es el libro "el mundo indígena" que publica anualmente y que es de acceso gratuito en su página web. Existe una versión en castellano y otra en inglés.
} 
antropólogo y que además lo reivindica, en muchas ocasiones, me han respondido "pero él es distinto".

Si Rodolfo Stavenhagen no es antropólogo, ¿qué entienden entonces por antropología? O, mejor dicho ¿qué imagen les hemos dado los antropólogos para que estos representantes definan la antropología de una forma muy concreta? Quizás la mejor forma de responder a esta pregunta sea utilizar mi propia experiencia subjetiva. Hace algunos años, un representante de un pueblo indígena latinoamericano me comentó: "mire señor. A mi no me gustan los antropólogos. En xxxx hay un señor antropólogo que se pasa el día todo diciendo que no tenemos que vestir jeans, que no vayamos a la iglesia... y nosotros no le hacemos caso. Él viene a nuestra aldea, escribe libros y luego se lleva toda la plata. ¿Usted cree que eso está bien?". A lo que añadió otro representante que participaba en la conversación "Mire usted. Yo estudié en la universidad y sé todo lo que hicieron ustedes con nuestras culturas. Sé los libros que tienen, todo los que se llevaron de nosotros. ¿Y qué nos dejaron? Nada. Lo que necesitamos son abogados, gente de leyes, que nos ayuden a nosotros y no antropólogos". En este sentido, es posible decir que el Convenio no. 169 sobre pueblos indígenas y tribales de la Organización Internacional del Trabajo quizás haya hecho más por los pueblos indígenas que la suma de los escrito de la mayoría de los antropólogos que han trabajado con ellos en los últimos 100 años ${ }^{17}$.

Creo que esta percepción es el resultado de nuestra propia historia y, hasta cierto punto, presente. Si bien actualmente muchos de los trabajos que lleva a cabo la antropología contemporánea (algunos de los cuales han sido publicados recientemente en AIBR y aparecen recogidos en este número) han abandonado los clásicos trabajos culturalistas en los que se "explicaba cómo eran los otros", todavía es fácil encontrar textos de ese tipo (no creo que sea necesario mencionar ninguno de ellos e incluso puedo decir que yo mismo he escrito textos de ese tipo). De hecho, las propias enseñanzas universitarias dedican una gran parte de su currículum a enseñar monografías de pueblos "remotos" lo que hace que esta sea la imagen que de nosotros tengan aquellos que trabajan en otras ciencias sociales o tienen conocimientos someros de antropología. Aún sin negar el hecho feaciente de que cada vez más la antropología se aleja de ese campo y de los estudios de comunidad, la mayor implicación en el trabajo práctico y en el estudio de nuestras propias culturas, en lo relativo a los pueblos indígenas, es esta imagen la que parece seguir manteniéndose. Existe la visión del antropólogo como interprete de culturas, algo que tenía una justificación cuando todavía era difícil que los diferentes grupos humanos entraran en contacto y existían grandes dificultades para que todos los grupos hablaran por sí mismos (puesto que no se habían generalizado ni difundido los medios de comunicación y transporte contemporáneos, y estaban en su apogeo la discriminación para con los pueblos indígenas). La antropología fue utilizada para demostrar a la sociedad decimonónica y colonialista la humanidad y la igualdad intrínseca de todos los seres humanos, entre otras muchas

\footnotetext{
${ }^{17}$ El Convenio 169 es uno de los grandes incomprendidos fuera del ámbito de las organizaciones que trabajan en la defensa de los derechos de los pueblos indígenas. En más de una ocasión he comprobado que ciertas personas con conocimientos en la materia consideran que el convenio ha sido ratificado por muy pocos países (17) y que muchos de ellos no son capaces de implementar sus disposiciones. No obstante, esta cuestión está mucho más ligada al sistema internacional en general (donde las organizaciones multilaterales, como la ONU, tienen una escasa capacidad para hacer valer los compromisos adquiridos por
} 
cosas, lo cual ayudó, hasta cierto punto, a crear una conciencia general sobre la necesidad de establecer unos derechos humanos universales y mecanismos de protección.

No obstante, en la actualidad, una vez que los medios de comunicación se han desarrollado y generalizado y esta conciencia de intrínseca igualdad se ha establecido, esa necesidad de interpretación o, incluso, de "portavoz" ha dejado de tener importancia: los pueblos indígenas solicitan hablar por ellos mismos, ser sus propios portavoces y ser ellos mismos los que expliquen cómo son y cómo viven. Mi propia y limitada experiencia me muestra que la práctica totalidad de pueblos indígenas del mundo participan, de un modo $u$ otro, de organizaciones o movimientos para la defensa de sus derechos ${ }^{18}$.

En los últimos años, un número cada vez mayor de antropólogos ha ido trabajando desde una perspectiva más aplicada y centrada en las demandas que los propios informantes tienen. Ya incluso en los años 50, varios antropólogos entendieron que la mejor forma de hacer antropología era formar a los propios miembros de las comunidades para que ellos mismos fueran capaces de explicarse y de hecho, en la actualidad esta forma de trabajo de hecho es muy habitual en el ámbito de la antropología latinoamericana, aunque no tanto entre los antropólogos europeos.

No obstante, mi experiencia en la antropología académica me indica que todavía la mayor parte de los trabajos realizados por ella van dirigidos a la misma academia y no suelen salir de dichos círculos. Si bien otras ciencias sociales (como pueden ser la economía, la psicología social, la ciencia política o la sociología) también dirigen sus estudios hacia cuestiones teóricas o hacia el propio desarrollo de la ciencia, una gran parte de sus trabajos traspasan esas fronteras y se dirigen hacia un público más amplio. Para estos científicos sociales, el papel de la academia es la de proporcionar materiales teóricos que luego en el terreno y en los trabajos a realizar sobre realidades concretas, para que sean utilizados. Un buen ejemplo, y sin querer entrar en polémicas, son los trabajos realizados por el Banco Mundial donde, más allá de la perspectiva neoliberal que emplea, mantiene una estrecha relación con el mundo académico y sus informes suelen estar bastante "al día" de los avances teóricos.

En la antropología, este paso todavía no se ha asentado y, en el caso de los trabajos antropológicos con pueblos indígenas parece que dicha línea es aún más díficil de romper ${ }^{19}$. En este punto, creo conveniente volver a hacer referencia a una experiencia personal que tuvo lugar hace unos pocos meses, con motivo de una reunión con representantes indígenas y de minorías en Ginebra. Entre las personas invitadas a participar había una mujer Kachin de Myanmar (antigua Birmania) y un hombre

los estados. No obstante, el convenio 169 supuso un hito y es todavía uno de los instrumentos más eficaces para la protección de los derechos de los indígenas.

${ }^{18}$ Esto no quiere decir que todas las comunidades o subgrupos participen de ellos, sino que hay alguna organización formada por miembros de ese mismo pueblo (o con representación) que se encarga de ser el interlocutor entre la sociedad envolvente y los pueblos indígenas.

${ }^{19}$ En buena medida creo que se debe a que la antropología, al menos en España, no ha conseguido abrirse un nicho de mercado en el ámbito de las ciencias sociales y son muy pocos los antropólogos que trabajan en el ámbito privado como 
Nuer. Ambos son defensores de los derechos humanos ${ }^{20}$ en sus propias comunidades $y$ han realizado estudios universitarios. La contestación de ambos fue bastante similar cuando les comenté la existencia de estudios clásicos de antropología sobre sus nacionalidades. La mujer Kachin me señaló que no conocía los trabajos de E. Leach pero que "estaría bien leer algo sobre cómo los europeos nos veían hace 50 años". Por su parte, la persona de origen Nuer sí conocía el trabajo de Evans-Pritchard. Su respuesta fue similar: "he leído el libro y le conté lo que ponía a mis padres, tíos y abuelos. Ni ellos ni yo nos vimos reflejado en ningún momento por lo que decía el libro. Algunas cosas sí, pero no el conjunto". Creo que ambas críticas son muy apropiadas por cuanto reflejan el enfoque que tradicionalmente se ha dado al estudio de pueblos indígenas ${ }^{21}$ y la escasa permeabilidad que estos han tenido en los pueblos estudiados. También fue interesante observar la falta de reconocimiento de aplicabilidad práctica del texto de Evans-Pritchard por parte de dicho representante ${ }^{22}$.

No obstante, las críticas al trabajo de los antropólogos y las suspicacias que he levantado cuando me he presentado como tal ante los representantes de pueblos indígenas, también puede extenderse a los especialistas de otras ciencias que trabajan con los pueblos indígenas o en cooperación para el desarrollo. Mi experiencia ha sido muy parecida a la anteriormente mencionada, aunque con algunos matices. En primer lugar, quiero destacar las palabras de un especialista del desarrollo con el que estuve trabajando hace un tiempo. Decía así "mira, yo llevo trabajando en este mundo muchos años y te digo que los antropólogos no habéis hecho mucho. Los que me he encontrado me hablan de cultura, de los derechos de las poblaciones locales, de cómo la cooperación no entiende nada y que son ellos los que saben. Más de una vez me he encontrado implementando un proyecto, escuchando a la comunidad local su apoyo al proyecto y apareciendo después por mi despacho un antropólogo me dice que no sabemos lo que estamos haciendo, que vamos a arruinar la vida de esa gente y que 'ellos no saben lo que supone la entrada del proyecto' (refiriéndose a los beneficiarios). Vamos, que son idiotas y que el antropólogo es el que nos va a explicar todo". Una revisión a algunos de los textos de la antropología del desarrollo contemporánea [como los conocidos textos de Gustavo Esteva (1992) o Arturo Escobar (1995), por ejemplo], nos lleva a no poder, cuando menos, estar hasta cierto punto de acuerdo.

A esta primera crítica se le puede añadir una segunda también bastante habitual. "Parece que son los únicos que saben. Los demás llevamos 30 años en esto pero parece que nunca sabemos nada, y un recién licenciado en antropología se atreve a decirlo porque 'él sí entiende a la gente'. Vamos, los

\footnotetext{
antropólogos y que no pertenecen al ámbito universitario. Esto impide que los trabajos más "aplicados" puedan mostrar al resto de la población la utilidad de la antropología.

${ }^{20}$ Figura creada por el Alto Comisionado para reconocer la labor que ciertas personas ejercen en la defensa de los derechos humanos. Tienen una declaración en la que se recogen una serie de derechos y se ha creado la figura del Representante del Secretario General para los Defensores de los Derechos humanos, cuya labor consiste en investigar las violaciones de derechos humanos que puedan sufrir estas personas específicas en el desempeño de su labor.

${ }^{21}$ No obstante, existen un gran número de casos en los que los trabajos realizados por antropólogos revierten en las propias comunidades. Como me señalaba un antropólogo africanista, sus estudios sobre una etnia africana los repartía entre las comunidades de esa etnia. Me comentaba que era interesante observar como estas mismas comunidades leían sus textos y luego lo utilizaban para explicar a otros como ellos eran.

${ }^{22}$ A pesar de que en este texto se presenta como un caso aislado, lo creo paradigmático de mi experiencia con representantes indígenas.
} 
demás nos hemos pasado nuestra vida sin preocuparnos por nada, sin pensar, y sin reflexionar sobre las cosas. No fastidies... y además, ¿ellos para qué sirven?". Este comentario, hecho por otro experto en desarrollo, creo que es bastante certero. La falta de respeto a los demás especialistas y autoconsiderarse poseedor de un conocimiento único, más que poder aupar a la antropología a un cierto liderazgo, lo que hace ciertamente es crear un recelo entre los otros científicos sociales y profesionales, sobre todo entre aquellos que trabajan directamente con las comunidades beneficiarias. Considero que sólo a través de la humildad y la práctica diaria, mostrando la utilidad de nuestra perspectiva y análisis, transigiendo y buscando acuerdos con otros científicos sociales, y reconociendo nuestras potencialidades y limitaciones (conozco muy pocos antropólogos que sean capaces de utilizar correctamente la estadística y tengan ligeras nociones de economía), será posible ocupar un lugar dentro del mundo de la cooperación en general y de los pueblos indígenas en particular.

\section{El papel de la antropología en la protección de los derechos de los pueblos indígenas}

¿Ahora bien, cuál es el papel que creo que debe ocupar la antropología dentro de este campo? En primer lugar, estoy convencido de que debe ser un papel central, pero debe seguir el ejemplo de Rodolfo Stavenhagen y Alda Nicolaisen. En pocas palabras, dentro de los equipos de cooperación para el desarrollo creo que nuestra labor debe ser la de observar los hechos desde una perspectiva micro, evitar generalizaciones innecesarias, resaltar la importancia del detalle, reconocer el papel del individuo y de la colectividad, ser conscientes de lo que hay detrás de los conceptos y los comportamientos, ser respetuoso con los grupos con los que se trabaja y ofrecer algo a cambio. En ningún caso, cuando se trabaja con comunidades beneficiarias, nuestra labor consiste en imponernos a la libertad de los grupos con los que trabajamos, hacer de portavoces sin ser solicitados, explicarles lo que deben hacer y oponernos a la "aculturación" (funesta palabra) cuando esta responde a un proceso en el que participan. En este caso, me gustaría referirme a una anécdota que viví hace ya más de 6 años con un antropólogo que trabajaba en Guinea-Bissau. Me comentaba su oposición frontal a que se instalaran tejados de aluminio en las aldeas del interior del país ya que era un paso más dentro del proceso de rápida aculturación que estas poblaciones estaban supuestamente viviendo. Esta visión suponía darle mucha más importancia a la propia "cultura" que a las personas que en ella vivían. Mi trabajo allí me mostró que la gente ahorraba para tener tejados de aluminio porque, más allá de ser una muestra de prestigio, evitaba la entrada de ratas y limitaba el número de avisperos dentro del hogar. Lo mismo puedo decir de mi experiencia en los barrios pobres de una ciudad brasileña (Santa Cruz do Sul). Uno de los datos más interesantes era el elevado número de antenas parabólicas en dichos barrios. En más de una ocasión escuché protestas del tipo "no tienen dinero para comer pero se compran antenas parabólicas". Consideremos acertada o no la elección de comprar antenas parabólicas (la cuestión de las antenas parabólicas es bastante compleja como para explicarla en unas pocas líneas), las personas tienen la libertad de emplear sus ingresos en aquello que consideren oportuno, sin que el antropólogo de turno tenga que criticarlo o buscar explicaciones 
de aculturación. En caso contrario estaríamos considerándoles, en la mejor de las opciones, menores de edad. Creo que muchos de nosotros consideraríamos inapropiado que alguien nos criticara por pasar una gran parte de nuestra vida encerrados leyendo libros o escribiendo artículos de muy escasa difusión.

Es en este punto donde me gustaría regresar al proceso de discusión de la estrategia, como ejemplo del tipo de trabajo que considero adecuado. La discusión de la estrategia se enmarcó en este proceso y en esta forma de entender la antropología. En primer lugar, el centro de la discusión se refirió al reconocimiento de los derechos de los pueblos indígenas, principalmente en lo relativo a sus tierras y territorios y en su derecho a decidir por sí mismos, que son los temas centrales que están defendiendo en el ámbito internacional. Si se les quiere considerar mayores de edad, no sólo ellos son los que tienen que decidir, sino que también tienen que ser capaces de hablar por ellos mismos y nosotros tener que respetar sus preferencias y recomendaciones en los procesos consultivos.

Es por ello también por lo que la cultura tuvo una posición secundaria en la discusión y siempre estuvo referida a procesos históricos o a derechos, por lo que poco interés tienen las investigaciones sobre las culturas antropológicas. En ningún momento se define el contenido de esa cultura, sino que son ellos los que tienen la libertad de cambiarla, de aceptar nuevos rasgos o de decidir mantenerlos. Es interesante reconocer que muchos representantes de pueblos indígenas tienen menos miedo a la globalización en el ámbito cultural que en el económico, y como son ellos los que solicitan el acceso y control de nuevas tecnologías "aculturadoras" ${ }^{\prime 2}$. Por el contrario, parece que muchos antropólogos que trabajan directamente con estos pueblos consideran nefastos este tipo de cambios. Hay veces que parecer necesario recordar que las comunidades no pertenecen a aquel que las investiga, sino a los habitantes que en ella viven.

Esto no quiere decir que en la discusión no se fuera consciente de que la Cooperación Española no tenga ninguna capacidad de decisión y que tendría que apoyar acríticamente los proyectos presentado por pueblos indígenas. Se reconoció que era necesario aceptar que la cooperación española no podría apoyar proyectos contrarios a los principios generales en los que se basa, como el respeto y promoción de los derechos humanos y que están recogidos en la Ley de Cooperación y en los sucesivos Planes Directores. Se consideraba, no obstante, que debía ser una discusión entre "iguales" y ambas partes "tenían algo que decir". Al igual que la cooperación española podría decidir si financiar o no, los pueblos indígenas tendrían la capacidad de rechazar cualquier propuesta. De cualquier forma, este conflicto es menor de lo que pudiera parecer por cuanto la discusión del contenido de la estrategia se basó en las necesidades que los propios pueblos indígenas han exprimido tanto en las consultas habidas como en el ámbito internacional. Quizás la mejor forma de

\footnotetext{
${ }^{23}$ Recientemente (8-9 de abril de 2006), en un seminario de expertos sobre migraciones indígenas organizado por el Foro Permanente para las Cuestiones Indígenas y por la Organización Internacional de Migraciones en el que participé junto con un buen número de representantes indígenas, estos pusieron el hincapié en como utilizar los efectos de las migraciones (remesas, conocimientos, redes sociales, etc.) en mejorar la situación de sus comunidades. Si bien se hizo especial hincapié en la necesidad de evitar que personas no indígenas habitaran en tierras indígenas sin su permiso, fue absolutamente secundaria la
} 
mostrar cómo se llega a adecuar los procesos de autodesarrollo con estos principios es utilizar el tratamiento que en la discusión se dio sobre la cuestión de la igualdad de género, uno de los principios básicos para la cooperación española ${ }^{24}$. Siguiendo la discusión, se propuso que la cooperación española podría promover procesos que fomenten la igualdad de género, pero para ello las iniciativas debían partir de las propias comunidades o de las organizaciones de mujeres indígenas. Estas, además, deberían controlar el proceso en todo momento y guiar los tiempos de la intervención. Así, la cooperación española podría favorecer procesos en favor de ciertos cambios sociales, siempre y cuando estos no fueran provocados desde el exterior, sino que surgieran dentro de las propias comunidades $^{25}$.

Una de las consecuencias de esta decisión se observa en la definición que se hizo en el proceso de la discusión de las líneas estratégicas. Cualquiera que analizara dichas líneas, muy probablemente considerará que estas no llegan a copar todo el universo o las necesidades a las que se enfrentan los pueblos indígenas, que hasta cierto punto no guardan una gran coherencia o parecen en algunos casos retazos inconexos. No obstante, estas son las prioridades que los propios pueblos indígenas nos transmitieron, con la salvedad de que se modificaron durante la discusión para que estuvieran en consonancia con los principios recogidos por la cooperación española.

En resumen, la perspectiva antropológica se plasamría en la discusión en la atención que se presta a las cuestiones micro, a la unión que se hace entre las demandas indígenas y las prioridades generales de la cooperación española, en la eliminación de generalidades y en la aceptación de la variedad de situaciones. Así, mi trabajo como antropólogo ha consistido, simplemente, en redactar en el vocabulario legal y de la cooperación al desarrollo las recomendaciones y necesidades que ellos, las organizaciones en defensa de los pueblos indígenas y expertos recogían, tomando en cuenta las particularidades, presentarlos de forma coherente con el resto de documentos de estrategia sectorial y con las normas de rango superior de la cooperación española, y, sobre todo, evitando cualquier imposición o limitación del futuro que deseen tener los pueblos indígenas. Con ello, la visión antropológica que defiendo, permite evitar que en el texto aparezcan estereotipos sobre los pueblos indígenas, se evite la justificación de imposiciones y, sobre todo, se les reconozca como actores de igual a igual, sin ningún tipo de política paternalista y el derecho a definir su futuro, sin que un texto se lo imponga. Por ello creo que en la futura ECEPI, una vez sea aprobada, será un texto con una clara influencia antropológica y su resultado final sólo podría haberse logrado por los antropólogos, puesto que no soy el único, que en ella han trabajado.

discusión sobre los efectos que tienen las migraciones sobre las culturas indígenas. El Foro Permanente para las Cuestiones Indígenas publicó un informe con los resultados del seminario

${ }^{24}$ La equidad de género aparece recogida en el Plan Director 2005-2008 tanto como prioridad sectorial y horizontal que debe ser respetado en todos los proyectos de desarrollo y como prioridad sectorial, lo que supone la financiación de proyectos cuyo fin es la igualdad de género.

${ }^{25}$ Esta es una cuestión que podría ser ampliamente discutida, puesto que el contexto en que dichos programas se crean o se desarrollan conllevan necesariamente modificaciones en las condiciones de vida y en las sociedades con las que se trabaja. Por ello, a pesar de indicarse que las migraciones evidentemente influían en la forma de vida de las comunidades, no se consideró especialmente negativo. 
Creo que para realizar esta labor, los antropólogos tenemos una formación ideal y que debería ser utilizada.

Si queremos cambiar la percepción que la totalidad de los representantes indígenas que he conocido durante mi trabajo en defensa de los derechos de los pueblos indígenas tiene sobre los antropólogos, es necesario que trabajemos para ellos o en aquellas áreas en las que podamos serles útiles, bajo su dirección última y control, y dejemos de lado las investigaciones centradas en sus culturas en las que el resultado no les revierte o, al menos, compaginemos nuestro interés científico con las necesidades y demandas de los pueblos con los que trabajamos. Si no, seguiremos siendo desprestigiados y negados por aquellos, los indígenas, con los que decimos trabajar. 


\section{Bibliografía}

\section{AECI (1997). Estrategia Española de Cooperación con los pueblos indígenas. Madrid: MAE-AECI}

Convenio número 169 de la Organización Internacional del Trabajo sobre pueblos indígenas y tribales en países independientes, aprobado el 27 de Junio de 1989. Accesible en http://www.ilo.org/ilolex/cgilex/convds.pl?C169

Declaración sobre el derecho y el deber de los individuos, los grupos y las instituciones de promover y proteger los derechos humanos y las libertades fundamentales universalmente reconocidos (A/RES/53/144), aprobado el 8 de marzo de 1999 por la Asamblea General de las Naciones Unidas

Documento de trabajo de la Presidenta-Relatora, Sra. Erica-Irene A. Daes, sobre el concepto de "pueblos indígenas", (E/CN.4/Sub.2/AC.4/1996/2). Informe del Grupo de Trabajo sobre las Poblaciones Indígenas de 10 de junio de 1996.

Escobar, A. (1995). Encountering development: the making and unmaking of the third world. Princeton: Princeton U.P.

Esteva, G. (1992). "Development”. En The development dictionary: a guide to knowledge as power. W. Sachs, Ed. Atlantic highlands: Zed Books.

IWGIA (anual). El Mundo Indígena. Copenhague: IWGIA

MAEC (2005). Plan Director de la Cooperación Española 2005-2008. Madrid: MAEC. Accesible en http://www.maec.es/NR/rdonlyres/63D1D276-85B5-41C4-BE6697678A6BC292/0/Plan Director Esp.pdf

Report of an expert workshop on indigenous peoples and migration: challenges and opportunities (Ginebra: 6-7 de abril de 2006), (E/C.19/2006/CRP.5), del Foro Permanente para las Cuestiones Indígenas. Accesible en http://uww.un.org/esa/socdev/unpfii/documents/5session crp5 migration.doc

Resolución por la que se aprueba el Proyecto de Declaración de las Naciones Unidas sobre los Derechos de los Pueblos Indígenas (HRC/2006/2) aprobada por el Consejo de Derechos Humanos el 29 de junio de 2006. (Nombre oficial: aplicación de la resolución 60/251 de la Asamblea General, de 15 de marzo de 2006, titulada "consejo de derechos humanos". Grupo de Trabajo de la Comisión de Derechos Humanos encargado de elaborar un proyecto de declaración de conformidad con el párrafo 5 de la resolución 49/214 de la Asamblea General, de 23 de diciembre de 1994) Accesible en ODS temporalmente bajo la signatura provisional A/HRC/1/L.3. 